\title{
Telemedicine has more than a remote chance in prisons
}

Telemedicine is at a tipping point in the US. Correctional systems in more than two dozen states are already relying on the approach, which uses video and other transmittable information rather than direct patient-doctor contact. Now, California, home to the largest correctional system in the country, is considering whether to make telemedicine a key part of health care for its more than 160,000 inmates.

It's an intriguing idea for the Golden State: telemedicine cuts the travel and security expenses that normally come with inmate care, and California is currently facing a nearly $\$ 20$ billion budget deficit. One proposal, which also recommends making prison care the responsibility of the University of California (UC) system, could save an estimated \$12-16 billion over the course of a decade.

The UC schools might also expect other benefits from the proposal. By taking on the inmate community, the five state medical schools can fulfill their mission of addressing health disparities and educating their students with a variety of populations and illnesses, some of them rarely seen outside of prison.

"There's also a tremendous opportunity for research," says Alexander Vo, executive director of the University of Texas Medical Branch (UTMB) Center for Telehealth Research and Policy in Galveston, which tracks a similar telemedicine endeavor in Texas. Vo notes that the large inmate populations within

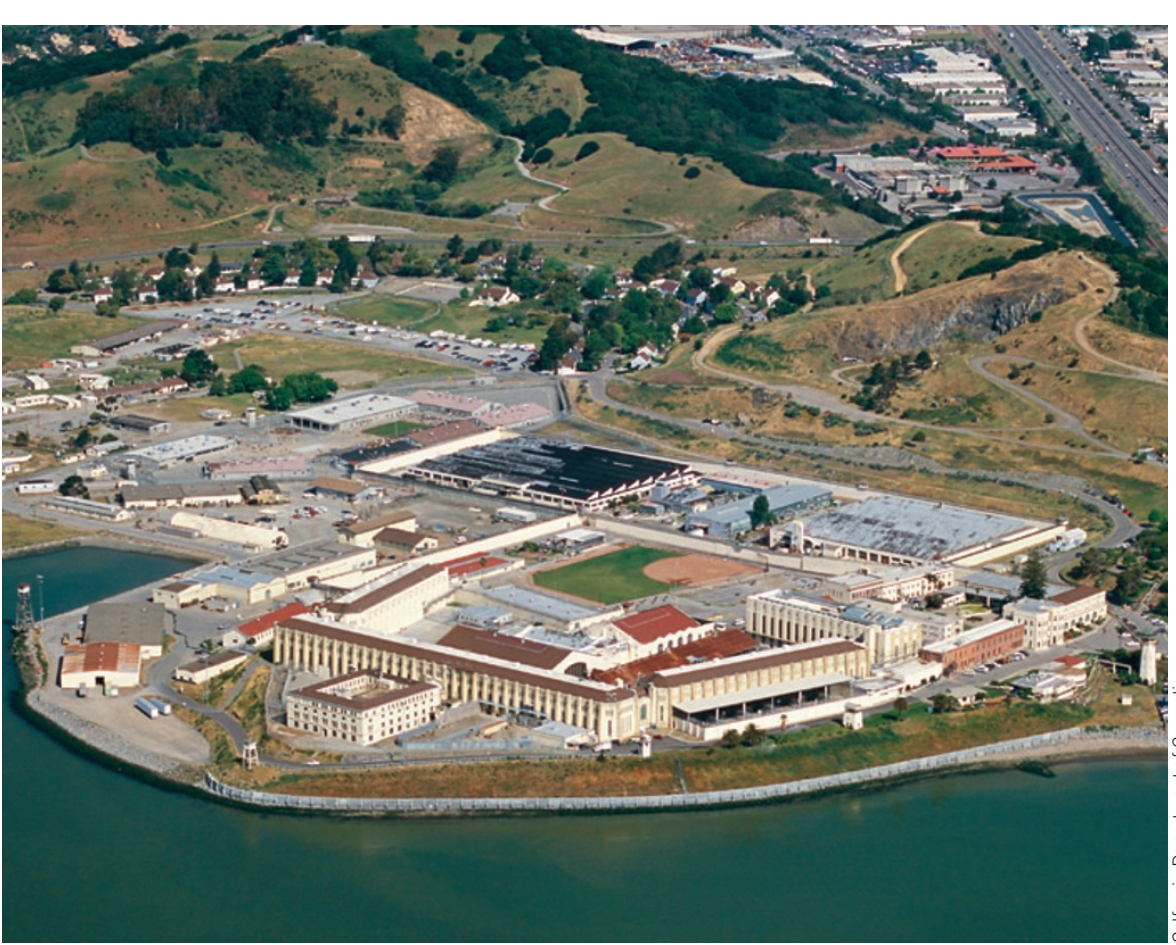

The long view: The proposed changes might affect San Quentin State Prison (pictured). prisons could translate into a potential pool of participants in studies of new technologies, as well as in comparative-effectiveness research. He adds, though, that prisoners are also a "protected population," and studies of them need to be carefully considered.

Aside from these purported benefits, however, detractors say that the current telemedicine proposal involving the UC system is too drastic. The Union of American Physicians and Dentists, among them 800 doctors currently employed by the California correctional system, argues not only that the UC system is inexperienced with handling prison care, but also that telemedicine would be too heavily relied upon, and thus quality of care would suffer.

"There's telemedicine already in place in the California [correctional] system, but the current proposal would dramatically expand it and replace numerous doctors with the work of a few," says Sue Wilson, a spokesperson for the union.

\section{The Lone Star system}

A growing number of states are using extensive telemedicine in their prisons. A few, including New Jersey and Georgia, use it in combination with university-run care. That said, Texas probably serves as the best model for the California proposal. In the 1990s, the Lone Star State formed Texas Correctional Managed Health Care, a partnership between the state corrections department, UTMB and Texas Tech University in Lubbock. Total savings were estimated at nearly $\$ 215$ million within the first six years, and the implementation of telemedicine was also linked to improvements in inmates' blood glucose levels, cholesterol and hypertension (J. Am. Med. Assoc. 282, 485-489, 2004).

Ben Raimer, former head of the UTMB Correctional Managed Care, says that telemedicine was successful in the state because the technology was so advanced ("just about every routine exam" can be performed, he says) and because telemedicine was just one part of "comprehensive electronic health," employing online pharmacy management and electronic medical records, as well.

Texas's success with telemedicine itself even led to a for-profit spin-off from UTMB: NuPhysicia. The Houston-based company is now serving as the main consultant for California, in fact, and wrote the proposal estimating the \$12-16 billion in savings. Having NuPhysicia behind the California proposal, however, hasn't helped the cause. Wilson, for example, says that a for-profit company shouldn't be evaluating California's system and then "selling" its services.

Meanwhile, others have raised concern over the involvement of John Stobo, the UC system's senior vice president for health sciences and services, because he was previously on NuPhysicia's board of directors. But both Stobo and the company counter that all ties were severed in September 2008, when Stobo left for the position in California.

Although Stobo has indeed been very supportive of the California proposal, he told Nature Medicine that the approach is "not for everybody." Some find it impersonal, but Stobo described how, at the end of one session, an inmate in Texas got up and extended his arm to shake the hand of his doctor-only to remember the 'doctor' was just a video screen. Stobo also says that the UC regents "need to exercise extreme caution" and evaluate whether a UC takeover of care is, in fact, doable.

Educators seem to agree. "This is a very complicated issue that we're going to have to spend a great deal of time to understand how or if UC can be involved," said Russell Gould, UC regents chairman, in a statement issued after a meeting in late March. At the meeting, the regents decided to establish a committee that would further probe the NuPhysicia proposal, as well as the general idea of telemedicine combined with UC-handled care.

Christian Torres, New York 